\title{
Effect of Post-Deposition Annealing on the Structural, Optical and Electrical Properties of Ti-doped Indium Oxide Thin Films
}

\author{
Sung-Bo Heo ${ }^{1,2}$, Hyun-Joo Moon ${ }^{1}$, Jeong-Hyeon $\mathrm{Oh}^{1}$, Young-Hwan Song ${ }^{1}$, Tae-Young Eom ${ }^{1}$, \\ Jun-Ho Kim², and Daeil Kim ${ }^{1, *}$ \\ ${ }^{I}$ School of Materials Science and Engineering, University of Ulsan, Ulsan 44610 , Republic of Korea \\ ${ }^{2}$ Korea Institute of Industrial Technologies (KITECH), Yangsan 44610, Republic of Korea
}

\begin{abstract}
Ti-doped $\mathrm{In}_{2} \mathrm{O}_{3}$ (TIO) thin films were deposited on glass substrates by $\mathrm{RF}$ magnetron sputtering. The films were then annealed at 100,200 or $300^{\circ} \mathrm{C}$ for $30 \mathrm{~min}$ to investigate the effects of the annealing temperature on the films' structural, electrical and optical properties. The films annealed at $200{ }^{\circ} \mathrm{C}$ and above were polycrystalline in phase, and their electrical resistivity decreased to as low as $7.5 \times 10^{-4} \Omega \mathrm{cm}$ at the annealing temperature of $300^{\circ} \mathrm{C}$. The films' optical transmittance in the visible wavelength region also improved from $77.7 \%$ to $81.2 \%$ when the annealing temperature was increased. The TIO films' figures of merit were evaluated, showing that the TIO films annealed at $300{ }^{\circ} \mathrm{C}$ had better optical and electrical performance than the other films prepared using lower-temperature or no annealing.
\end{abstract}

(Received February 9, 2016; Accepted May 10, 2016)

Keywords: thin film, sputtering, electrical properties, $x$-ray diffraction, figure of merit.

\section{INTRODUCTION}

Recently, Ti-doped $\mathrm{In}_{2} \mathrm{O}_{3}$ (TIO) films have attracted great attention for their potential application in various display devices due to their high stability in humid conditions and their low electrical resistivity [1]. In addition, TIO films have shown higher carrier mobility than conventional Sn-doped $\mathrm{In}_{2} \mathrm{O}_{3}$ (ITO) [2]. Various deposition methods have been used to obtain high-quality TIO films, including magnetron sputtering [3] and pulsed laser deposition [4].

Among the various deposition methods that are available, $\mathrm{RF}$ magnetron sputtering is the most widely used due to its ability to produce uniform films over large areas. However, it is well known that transparent conductive oxide films prepared at room temperature by RF magnetron sputtering have relatively low optical transmittance in the visible light range and high electrical resistivity [5,6]. Thus, the optical and electrical properties of conventional TIO films deposited at room temperature do not meet the typical demands of optoelectronic applications.

In a previous study, D. Kim investigated the effect of substrate temperature on the properties of $480 \mathrm{~nm}$ thick TIO

*Corresponding Author: Daeil Kim [Tel: +82-52-259-2243, E-mail: dkim84@ulsan.ac.kr] Copyright (c) The Korean Institute of Metals and Materials films deposited on glass substrate [7] and A. Chaoumead also reported on the influence of sputtering power and gas pressure on the structural and electrical properties of TIO films deposited by RF magnetron sputtering [8].

In this study, TIO thin films deposited by RF magnetron sputtering were annealed under vacuum, and the influence of different annealing conditions on the films' structural, electrical and optical properties were investigated by means of X-ray diffraction (XRD) analysis, UV-visible spectrophotometry, Hall Effect measurements, and atomic force microscopy (AFM).

\section{EXPERIMENTAL PROCEDURES}

TIO films were deposited at room temperature on glass substrates $\left(30 \times 30 \mathrm{~mm}^{2}\right)$ by $\mathrm{RF}$ magnetron sputtering with a TIO target ( $\mathrm{Ti}: \mathrm{In}_{2} \mathrm{O}_{3}=5: 95$ at $\% ; 99.99 \%$ purity). Prior to each deposition, the chamber was evacuated to $6 \times 10^{-7}$ Torr, and the distance between the target and the substrate was kept constant at $60 \mathrm{~mm}$. Table 1 shows the experimental conditions used for this study.

After deposition, the films were annealed at $1 \times 10^{-3}$ Torr for $30 \mathrm{~min}$ at various annealing temperatures; the maximum annealing temperature used was $300{ }^{\circ} \mathrm{C}$ to prevent thermal 
Table 1. The deposition conditions of TIO thin films.

\begin{tabular}{cc}
\hline Parameter & Conditions \\
\hline Thickness $(\mathrm{nm})$ & 100 \\
\hline Base pressure (Torr) & $6.0 \times 10^{-7}$ \\
\hline Deposition pressure $($ Torr $)$ & $1.0 \times 10^{-3}$ \\
\hline Target power $\left(\mathrm{W} / \mathrm{cm}^{2}\right)$ & Pulsed DC, 2.2 \\
\hline Pulse frequency $(\mathrm{kHz})$ & 20 \\
\hline Ar gas flow rate $(\mathrm{sccm})$ & 20 \\
\hline Film thickness $(\mathrm{nm})$ & 100 \\
\hline Deposition rate $(\mathrm{nm} / \mathrm{min})$ & 12 \\
\hline Annealing temperature $\left({ }^{\circ} \mathrm{C}\right)$ & $100,200,300$ \\
\hline
\end{tabular}

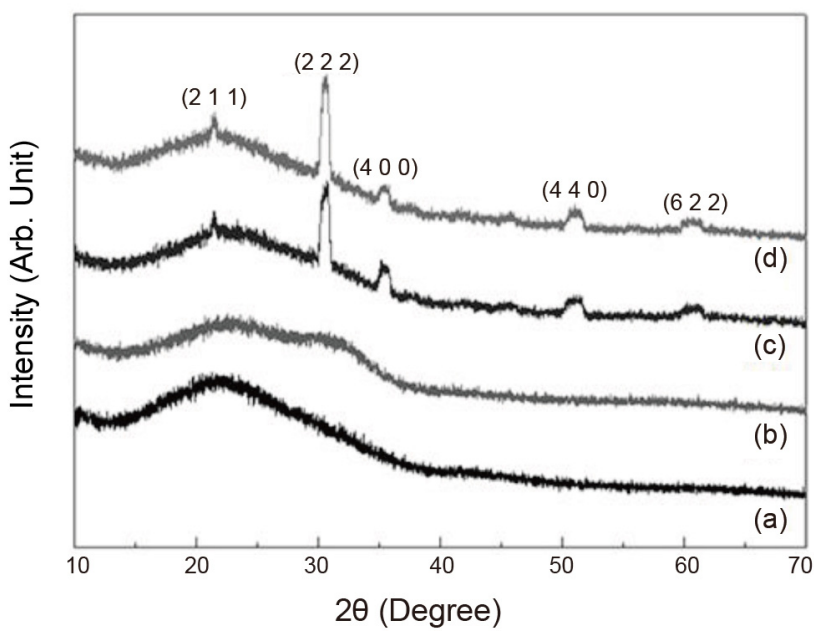

Fig. 1. The XRD pattern of the TIO films annealed at different temperatures. (a) As deposition, (b) Annealed films at $100{ }^{\circ} \mathrm{C}$, (c) Annealed films at $200{ }^{\circ} \mathrm{C}$, (d) Annealed films at $300{ }^{\circ} \mathrm{C}$.

deformation of the glass substrate. The film thickness was confirmed using a surface profilometer and the root mean square (RMS) roughness of the films was analyzed by means of AFM (XE-100, Park Systems).

The crystallization of the films was observed by means of high-resolution XRD (X'Pert Pro MRD, Philips), conducted at the Daegu Center of the Korea Basic Science Institute (KBSI). The optical transmittances and electrical properties of the films annealed at various temperatures were evaluated by means of UV-visible spectrophotometry (Cary100 Cone, Varian), and van der Pauw Hall effect measurements (HMS-3000 Ecopia) were acquired under a magnetic flux density of $0.5 \mathrm{~T}$. The performance of the TIO films as transparent conducting films was quantified using the figure of merit (FOM) [9].
Table 2. Variation of the grain size as a function of annealing temperature.

\begin{tabular}{ccc}
\hline Temperature $\left({ }^{\circ} \mathrm{C}\right)$ & FWHM $\left({ }^{\circ}\right)$ & Grain size $(\mathrm{nm})$ \\
\hline As deposition & - & Amorphous \\
\hline 100 & - & Amorphous \\
\hline 200 & 2.0 & 4.1 \\
\hline 300 & 1.2 & 7.1 \\
\hline
\end{tabular}
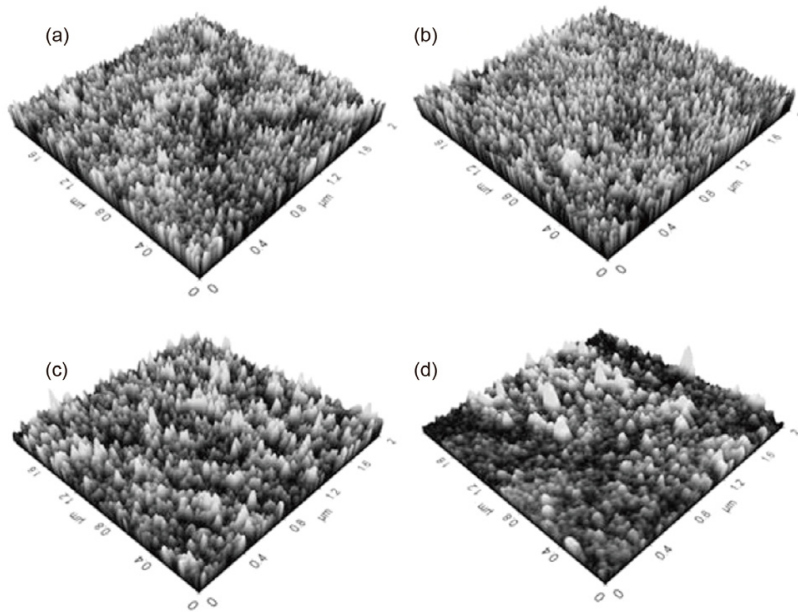

Fig. 2. Surface morphology (scan area; $2 \times 2 \mu \mathrm{m}^{2}$ ) and RMS roughness of the TIO films annealed at different temperatures. (a) As deposition, RMS roughness; $0.87 \mathrm{~nm}$, (b) Annealed films at $100{ }^{\circ} \mathrm{C}$, RMS roughness; $1.09 \mathrm{~nm}$, (c) Annealed films at $200{ }^{\circ} \mathrm{C}$, RMS roughness; $1.90 \mathrm{~nm}$, (d) Annealed films at $300{ }^{\circ} \mathrm{C}$ RMS roughness; $2.11 \mathrm{~nm}$.

\section{RESULTS AND DISCUSSION}

XRD patterns were acquired from the as-deposited TIO films, and from the TIO films that were subjected to post-deposition annealing at 100, 200 and $300{ }^{\circ} \mathrm{C}$. In Fig.1, the films deposited at room temperature do not show any diffraction peaks, whereas those films annealed at 200 and $300{ }^{\circ} \mathrm{C}$ show diffraction peaks corresponding to the (211), (222), (400), (440) and (622) planes of $\mathrm{In}_{2} \mathrm{O}_{3}$ films. The full width at half maximum of the $\operatorname{In}_{2} \mathrm{O}_{3}$ (222) peak decreased with increasing annealing temperature, meaning that increasing the temperature enhanced the films' crystallization.

Table 2 lists the grain sizes of the films as evaluated using Scherer's formula [10]. The films annealed at $300{ }^{\circ} \mathrm{C}$ showed the largest grain size of $7.1 \mathrm{~nm}$ as measured on the $\mathrm{In}_{2} \mathrm{O}_{3}$ (222) plane. 
Table 3. The dependence of the electrical properties of the films on annealing temperature.

\begin{tabular}{cccc}
\hline $\begin{array}{c}\text { Temperature } \\
\left({ }^{\circ} \mathrm{C}\right)\end{array}$ & $\begin{array}{c}\text { Carrier density } \\
\left(\times 10^{20} \mathrm{~cm}^{-3}\right)\end{array}$ & $\begin{array}{c}\text { Mobility } \\
\left(\mathrm{cm}^{2} \mathrm{~V}^{-1} \mathrm{~S}^{-1}\right)\end{array}$ & $\begin{array}{c}\text { Resistivity } \\
\left(\times 10^{-3} \Omega \mathrm{cm}\right)\end{array}$ \\
\hline As deposition & 6.59 & 8.32 & 1.14 \\
\hline 100 & 6.78 & 8.45 & 1.09 \\
\hline 200 & 7.28 & 9.43 & 0.90 \\
\hline 300 & 8.19 & 10.11 & 0.75 \\
\hline
\end{tabular}

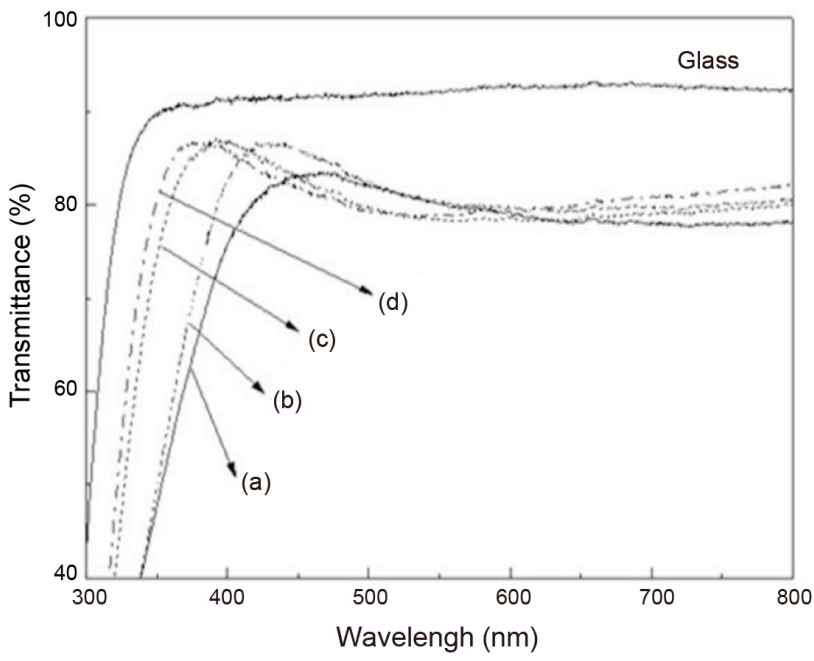

Fig. 3. The optical transmittance spectra in the visible wavelength region for the as-deposited and the annealed TIO films. (a) As deposition, (b) Annealed films at $100{ }^{\circ} \mathrm{C}$, (c) Annealed films at $200{ }^{\circ} \mathrm{C}$, (d) Annealed films at $300{ }^{\circ} \mathrm{C}$.

In Fig. 2, AFM images of the as-deposited and annealed TIO films show that the surface roughness increased with annealing temperature. The films annealed at $300{ }^{\circ} \mathrm{C}$ show the highest RMS roughness of $2.11 \mathrm{~nm}$. This increasing surface roughness its attributed to the grain growth of the films, which had already been observed from the XRD patterns.

Fig. 3 shows the visible regions of the optical transmittance spectra collected for the as-deposited and the annealed TIO films. The bare glass substrates showed 90\% optical transmittance. The average transmittance of the as-deposited films was about $77.7 \%$, and the film annealed at $300{ }^{\circ} \mathrm{C}$ had a transmittance of $81.2 \%$. This means that annealing increased the optical transmittance of visible light. In addition, it was observed that the absorption edges shifted towards shorter optical wavelengths with increasing annealing temperature. This hypsochromic shift of the absorption edge in the optical transmittance spectrum can be explained by the Burstein-

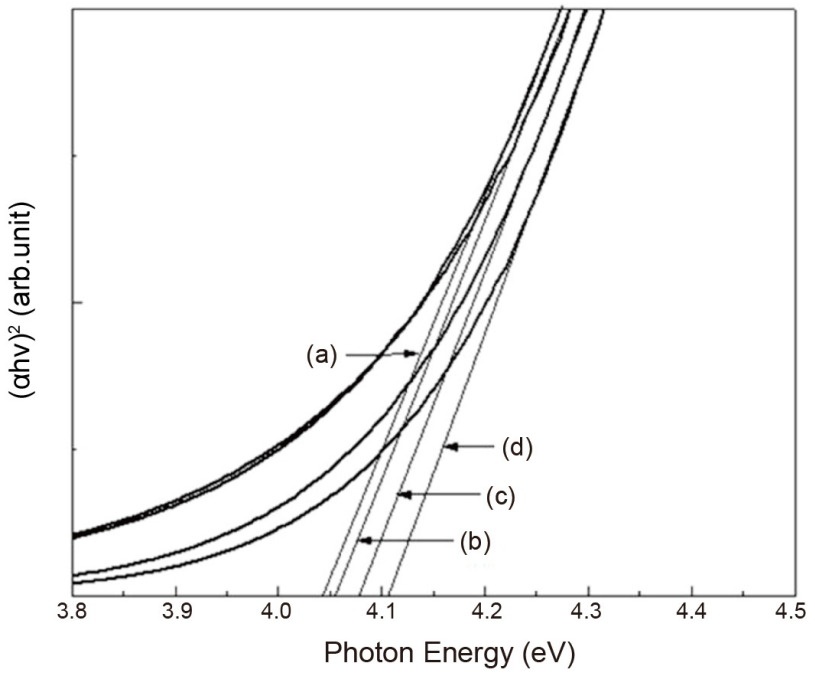

Fig. 4. Plots of $(\alpha h v)^{2}$ as a function of hv for TIO films annealed at different temperatures. The extrapolation of the linear region to $\mathrm{h} v=0$ to determine optical band gap $(\mathrm{Eg})$ values is as indicated with lines. (a) As deposition, (b) Annealed films at $100{ }^{\circ} \mathrm{C}$, (c) Annealed films at $200{ }^{\circ} \mathrm{C}$, (d) Annealed films at $300{ }^{\circ} \mathrm{C}$.

Moss effect [11], in which the absorption edge shifts toward shorter wavelengths in response to increasing carrier concentrations.

Table 3 shows the dependence of the films' electrical properties upon the annealing temperature. As the annealing temperature was increased from room temperature to $300{ }^{\circ} \mathrm{C}$, resistivity decreased from $1.1 \times 10^{-3}$ to $7.5 \times 10^{-4} \Omega \mathrm{cm}$ due to increases in both mobility and carrier concentration. Based on the XRD patterns and the results presented in Table 2, it is supposed that the observed decreases in resistivity with increasing annealing temperatures occurred because of grain growth, because grain growth reduces the density of grain boundaries, which act as traps for free carriers and as barriers to carrier movement.

Fig. 4 shows plots of $(\alpha h v)^{2}$ versus photon energy for the TIO films [12]. The optical absorption coefficient $(\alpha)$ can be calculated from the following relation [13]:

$$
\alpha=\frac{1}{t} \ln \left(\frac{1}{T}\right)
$$

where $\mathrm{t}$ is the film thickness and $\mathrm{T}$ is the optical transmittance. The relation between the optical absorption coefficient and the optical band gap $\left(E_{g}\right)$ is given by the Tauc 
Table 4. Variation of the optical band gap as a function of annealing temperature.

\begin{tabular}{ccc}
\hline Temperature $\left({ }^{\circ} \mathrm{C}\right)$ & Optical band gap $(\mathrm{eV})$ & Reference \\
\hline As deposition & 4.04 & This study \\
\hline 100 & 4.05 & This study \\
\hline 200 & 4.07 & This study \\
\hline 300 & 4.10 & This study \\
\hline GZO $100 \mathrm{~nm}$ & 3.87 & {$[15]$} \\
\hline
\end{tabular}

Table 5. The FOM values for TIO films annealed at different temperatures.

\begin{tabular}{cccc}
\hline $\begin{array}{c}\text { Temperature } \\
\left({ }^{\circ} \mathrm{C}\right)\end{array}$ & $\begin{array}{c}\text { Sheet resistance } \\
{[\Omega / \square]}\end{array}$ & $\begin{array}{c}\text { Transmittance } \\
{[\%]}\end{array}$ & $\begin{array}{c}\text { Figure of merit } \\
{\left[\Omega^{-1}\right]}\end{array}$ \\
\hline As deposition & 114 & 77.7 & $7.0 \times 10^{-4}$ \\
\hline 100 & 109 & 79.8 & $9.6 \times 10^{-4}$ \\
\hline 200 & 90.9 & 80.4 & $1.2 \times 10^{-3}$ \\
\hline 300 & 75.4 & 81.2 & $1.6 \times 10^{-3}$ \\
\hline
\end{tabular}

formula [14]:

$$
(a h \nu)^{2}=C\left(h \nu-E_{g}\right)
$$

where $\mathrm{h} v$ is the energy of the incident photons and $\mathrm{C}$ is the absorption edge width parameter.

Table 4 lists the optical band gaps of the TIO films annealed at various temperatures. All annealed films had wider optical band gaps than the as-deposited TIO films. The optical band gap of the TIO films shifted from 4.043 to $4.107 \mathrm{eV}$ with increases in annealing temperature from 100 to $300{ }^{\circ} \mathrm{C}$.

The FOM is an important index used to evaluate the performance of transparent conductive oxide films. The FOM is defined as

$$
\mathrm{FOM}=\mathrm{T}^{10} / \mathrm{Rs}
$$

where $\mathrm{T}$ is the film's optical transmittance in the visible region, and Rs is the film's sheet resistance. Table 5 lists the FOMs of the TIO films annealed at various temperatures. The maximum FOM of $1.6 \times 10^{-3} \Omega^{-1}$ was observed for the films annealed at $300{ }^{\circ} \mathrm{C}$. Since a higher FOM indicates better optical and electrical performance of the transparent conductive oxide film, it can be concluded that TIO films annealed at $300{ }^{\circ} \mathrm{C}$ would perform better than the films annealed at lower temperatures in this study.

\section{CONCLUSIONS}

TIO thin films were deposited onto unheated glass substrates by RF magnetron sputtering and then vacuum annealed at 100,200 and $300{ }^{\circ} \mathrm{C}$ for $30 \mathrm{~min}$.

TIO films annealed at $200{ }^{\circ} \mathrm{C}$ and above showed diffraction peaks corresponding to the (211), (222), (400), (440) and (622) planes of $\operatorname{In}_{2} \mathrm{O}_{3}$ films. The full width at half maximum of the $\mathrm{In}_{2} \mathrm{O}_{3}$ (222) peak decreased with increasing annealing temperature, indicating that hotter annealing enhanced the films' crystallization. The films annealed at $300{ }^{\circ} \mathrm{C}$ showed a lower resistivity of $7.5 \times 10^{-4} \Omega \mathrm{cm}$, and showed a higher optical transmittance of $81.2 \%$ in the visible spectrum.

Based on the observed results, it can be concluded that post-deposition vacuum annealing at an optimized temperature enhances both the optical and electrical properties of the as-deposited TIO films.

\section{ACKNOWLEDGEMENT}

This work was supported by the Korean Ministry of Trade, Industry and Energy, Korea (MOTIE) under Grant M0000529.

\section{REFERENCES}

1. Y. Abe, and N. Ishiyama, J. Mater. Sci. Lett. 41, 7580 (2006).

2. M. F. A. M. Van Hest, M. S. Dabney, J. D. Perkins, D. S. Ginley, and M. P. Taylor, Appl. Phys. Lett. 87, 032111 (2005).

3. M. Kim, J. W. Kim, and S. H. Lim, Met. Mater. Int. 21, 1101 (2015).

4. R. K. Gupta, K. Ghosh, S. R. Mishra, and P. K. Kahol, Appl. Surf. Sci. 253, 9422 (2007).

5. Y. M. Kong, M. K. Kim, and D. Kim, Korean J. Met. Mater. 52, 233 (2014).

6. P. Prepelita, V. Craciun, F. Garoi, and A. Staicu, Appl. Surf. Sci. 352, 23 (2015).

7. D. J. Kim, B. Kim, and H.K Kim, Thin Solid Films 547, 225 (2013).

8. A. Chaoumead, B. H. Joo, D. J. Kwak, and Y. M. Sung, Appl. Surf. Sci. 275, 227 (2013).

9. J. H. Jeon, T. K Gong, Y. M. Kong, H. M. Lee, and D. 
Kim, Electron. Mater. Lett. 11, 481 (2015).

10. J. Lim, J. Son, and J. Hong, Met. Mater. Int. 20, 551 (2014).

11. S. N. Svitasheva, and A. M. Gilinsky, Appl. Surf. Sci. 281, 109 (2013).

12. Y. Wang, W. Tang, L. Zhang, and J. Zhao, Thin Solid Films 563, 62 (2014).
13. X. Yin, W. Tang, X. Weng, and L. Deng, J. Phys. D; Appl. Phys. 42, 025104 (2009).

14. J. Tauc, Amorphous and liquid semiconductors, Plenum, New York (1974).

15. T. K. Gong, J. H. Jeon, S. B. Heo, B. Cha, J. Kim, U. Jung, S. Park, Y. Kong, and Daeil Kim, Korean J. Met. Mater. 54, 113 (2016). 